\title{
The Long And The Short Of eCommerce Intentions: Examining The Distinguishing Effect Of Time Orientation Between Behavioral Intentions And Behavioral Goals
}

Damon E. Campbell, Millsaps College, USA

D. Veena Parboteeah, Eastern New Mexico University, USA

\begin{abstract}
This study analyzes the distinction, both conceptually and operationally, between behavioral intentions and behavioral goals. This paper recognizes the importance of time orientation in the measurement of behavioral intentions, as defined by Fishbein and Ajzen (1975). Literature is reviewed that shows this conceptual definition is often misused in information systems (IS) research because behavioral intention is sometimes operationalized with a long-term time orientation (i.e., continued use). This paper offers an empirical assessment, in the context of online purchases, of the discriminant validity between behavioral intentions and behavioral goals. The results of the survey $(N=458)$ indicate that time orientation does distinguish these constructs in an eCommerce setting. Theoretical implications are that long-term oriented behavioral intentions actually represent behavioral goals and thus have less conceptual implications for predicting actual behavior. Practical implications indicate that such distinctions may influence eCommerce strategies for online impulse purchases as well as customer relationship management.
\end{abstract}

Keywords: Behavioral Intention; Behavioral Goal; Online Impulse Buying; Customer Relationship Management

\section{INTRODUCTION}

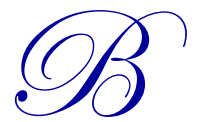

ehavioral intention has been an important variable in many electronic commerce (eCommerce) studies (e.g., Loiacono, Watson, \& Goodhue, 2007). According to the Theory of Reasoned Action (TRA) (Fishbein \& Ajzen, 1975), the Theory of Planned Behavior (TPB) (Ajzen, 1991) and applied frameworks, such as the Technology Acceptance Model (TAM) (Davis, Bagozzi, \& Warshaw, 1989), behavioral intention is considered an immediate antecedent of behavior (Davis et al., 1989). In the context of eCommerce, it has been found to be closely correlated with consumers' behavior online. For instance, behavioral intention has been used to predict behaviors such as making an online purchase (Van der Heijden, Verhagen, \& Creemers, 2003), intention to use a website (Gefen, Karahanna, \& Straub, 2003; Van der Heijden, 2004), intention to reuse a website (Loiacono et al., 2007), continued use (Bhattacherjee, 2001b), and revisiting a website (Van der Heijden, 2004), to name a few.

Although behavioral intention is often the ultimate endogenous variable in a research model, the link between intentions and actual behavior can be inhibited. In psychology, research has shown that there are inhibitors of both the intent to perform a behavior and the behavior itself (for a discussion, see Ajzen, 1991). Further, in IS research, knowledge and resources have been identified as "barriers to technology adoption intent (e.g., Mathieson, 1991; Taylor \& Todd, 1995) and actual usage behavior" (Taylor \& Todd, 1995)" (Venkatesh \& Brown, 2001, p. 76). Interestingly, eCommerce researchers have integrated behavioral intention in their research models with the 
assumption that the intention-behavior correlation will be strong in all cases, disregarding the occurrence of these potential inhibitors.

One of the inhibitors between the intention-behavior relationship is the time interval between the behavioral intention and the actual behavior (Fishbein \& Ajzen, 1975). The overarching goal of this study is to examine the effect of time interval on the intention-behavior relationship. More specifically, this study focuses on distinguishing between behavioral intentions that immediately precede behavior and behavioral goals which are focused on desired end states. The conceptual difference between these two constructs is the extent of time to the expected behavior. The theoretical implications of this distinction lie in the implications for predicting actual behavior.

In this paper, we focus on distinguishing between behavioral intentions and behavioral goals. We first review relevant literature to highlight the need for this conceptual distinction. We then explicitly define behavioral intentions and behavioral goals by reviewing the relevant literature. Additionally, we outline our study for empirically examining the discriminant validity of these constructs. Finally, the results of the study are discussed as well as the limitations and implications for theory and practice.

\section{LITERATURE REVIEW}

TAM is an extended version of the TRA framework that was adapted to a technology adoption context (Davis et al., 1989). In our literature review, we reviewed studies which have operationalized behavioral intentions over a 15 -year period, from acknowledged top IS journals ${ }^{1}$ which yielded a sample of 52 studies. While this review was not exhaustive, it does give a good indication of the use of behavioral intentions in IS research (see Table 1).

\begin{tabular}{|c|c|c|c|}
\hline Article & Context & Article & Context \\
\hline (Karahanna, Straub, \& Chervany, 1999) & Adopt/experiment & (Chang \& Cheung, 2001) & Use \\
\hline (Saade \& Bahli, 2005) & Use & (Hsu \& Lu, 2004) & Use \\
\hline (Lai \& Li, 2005) & Use & (Hu, Clark, \& Ma, 2003) & Use \\
\hline (Moon \& Kim, 2001) & Use & (Wixom \& Todd, 2005) & Use \\
\hline (Agarwal \& Karahanna, 2000) & Use & (Chau \& Hu, 2002b) & Use \\
\hline (Koufaris, 2002) & $\begin{array}{c}\text { Return/unplanned } \\
\text { purchase }\end{array}$ & (Hu, Chau, Sheng, \& Tam, 1999) & Use \\
\hline (AbdulGader \& Kozar, 1995) & Purchase & (Van der Heijden, 2004) & Revisit \\
\hline (Chen, Gillenson, \& Sherrell, 2002) & Use & (Chin, Marcolin, \& Newsted, 2003) & Use \\
\hline (Chen et al., 2002) & Purchase & & \\
\hline (Vijayasarathy, 2004) & Use & (Ong, Lai, \& Wang, 2004) & Use \\
\hline (Pennington, Wilcox, \& Grover, 2003) & Purchase & (Agarwal \& Prasad, 1998) & Use \\
\hline (Chau \& Hu, 2001) & Use & (Venkatesh, 2000) & Use \\
\hline (Venkatesh \& Davis, 1996) & Use & $\begin{array}{l}\text { (Hardgrave, Davis, \& } \\
\text { Riemenschneider, 2003) }\end{array}$ & Use \\
\hline (Venkatesh, Speier, \& Morris, 2002) & Use & (Hong, Thong, Wong, \& Tam, 2001) & Use \\
\hline (Agarwal \& Prasad, 1998) & Use & (Venkatesh \& Davis, 2000) & Use \\
\hline (Bagchi, Kanungo, \& Dasgupta, 2003) & Use & (Gefen et al., 2003) & Use \\
\hline (Lou, Luo, \& Strong, 2000) & Use & (Venkatesh \& Morris, 2000) & Use \\
\hline (Amoako-Gyampah \& Salam, 2004) & Use & $\begin{array}{l}\text { (Plouffe, Hulland, \& Vandenbosch, } \\
\text { 2001) }\end{array}$ & Adopt \\
\hline (Bhattacherjee, 2001a) & Continuance & (Van der Heijden, 2003) & Use/Visit \\
\hline (Bhattacherjee \& Premkumar, 2004) & Continuance & (Van der Heijden et al., 2003) & Purchase \\
\hline (Chau \& Hu, 2002a) & Use & (Agarwal \& Prasad, 1997) & Use \\
\hline (Lucas \& Spitler, 2000) & Use & (Bhattacherjee, 2001b) & Continuance \\
\hline $\begin{array}{l}\text { (Harrison, Mykytyn, \& Riemenschneider, } \\
\text { 1997) }\end{array}$ & Use & (Hsu \& Chiu, 2004) & Experiment/Use \\
\hline
\end{tabular}

\footnotetext{
${ }^{1}$ We used the journal ranking list which is available at www.aisnet.org as guide for the top 10 IS journals.
} 
Table 1 cont.

\begin{tabular}{|l|c|l|c|}
\hline $\begin{array}{l}\text { (Venkatesh, Morris, Davis, \& Davis, } \\
\text { 2003) }\end{array}$ & Use & $\begin{array}{l}\text { (Riemenschneider, Harrison, \& } \\
\text { Mykytyn, 2003) }\end{array}$ & $\begin{array}{c}\text { Have web } \\
\text { presence }\end{array}$ \\
\hline (Agarwal \& Prasad, 1999) & Use/Adopt & (Peace, Galletta, \& Thong, 2003) & Piracy \\
\hline $\begin{array}{l}\text { (Brown, Massey, Montoya-Weiss, \& } \\
\text { Burkman, 2002) }\end{array}$ & Use & (Dishaw \& Strong, 1999) & Use \\
\hline $\begin{array}{l}\text { (Garrity, Glassberg, Kim, Sanders, \& } \\
\text { Shin, 2005) }\end{array}$ & Use & & \\
\hline
\end{tabular}

These articles show that behavioral intention has been applied in various contexts and time orientations. For instance, behavioral intention has been used in various contexts, including intention to adopt, continued use, experiment with, have a web presence, commit piracy, purchase, return, unplanned purchase, revisit, and use an IS. Further, an inspection of the items used in these particular studies shows that some of the items explicitly state intentions as long-term (Van der Heijden et al., 2003) or short-term (Van der Heijden, 2004; Van der Heijden et al., 2003), while others give indications of specific time periods - e.g., 6 months (Brown et al., 2002; Harrison et al., 1997; Karahanna et al., 1999) and a year (Wixom \& Todd, 2005). The TAM study, which is largely cited in the justification of behavioral intention, actually uses an adoption context of two weeks (Davis et al., 1989). Although many of these studies in behavioral intention research refrain from referencing a specific time orientation, here we review the implications (conceptually and operationally) that time orientation has on the use of behavioral intention in IS research.

\section{Behavioral Intentions in IS Research}

Fishbein and Ajzen (1975) introduced TRA, which included a modern definition of intentions. According to them, behavioral intention "is a measure of the strength of one's intention to perform a specified behavior" (Fishbein \& Ajzen, 1975, p. 288). They also proposed that the strength of the intention-behavior relationship is theorized to diminish over time. More specifically, "given that intentions are subject to change between the time of intention measurement and behavioral performance, one would expect the intention-behavior correlation to diminish with increased elapsed time" (Fishbein \& Ajzen, 1975, p. 370). The correlation of intention to behavior is dependent on the intention's time orientation in relation to the behavior. Therefore, it is important to distinguish the difference between immediate intentions and longer-term goals.

Unfortunately, few studies in IS research consider the time orientation. However, some researchers have avoided the possibility of this inference by measuring the observed intention-behavior correlation (e.g., Venkatesh \& Davis, 2000). In this study, the influence that time orientation has on the use of behavioral intention in the context of e-Commerce is examined. The term 'behavioral goals' represents the longer-term goals that are theorized to have less predictive ability for actual behavior. Next, the distinction between behavioral goals and behavioral intentions is reviewed.

\section{Behavioral Goals}

Goals are "desired states one aims to attain" (Custers \& Aarts, 2005). A behavioral goal, therefore, would be the desire to behave in a specific way. Warshaw and Davis (1985a, p. 600) define behavioral goals as follows:

As formulated by Fishbein and Ajzen (1975), behavioral intention is the immediate psychological determinant of purely volitional behavior. Therefore, it does not apply when the probability of performing a behavior that is not consciously attempted is greater than 0.0 (e.g., habits) or when the probability of performing a behavior that is consciously attempted is less than 1.0 (e.g., behavioral impediments). The intention model is routinely, although inappropriately, applied in contexts where habits or impediments are operative (Warshaw et al., in press). We shall refer to behaviors where lack of ability, lack of opportunity, habits, or environmental impediments prevent the performance of attempted behavior as behavioral goals.

Similar conceptualizations of this concept have been labeled behavioral expectations (Warshaw \& Davis, 1985a) and desires (Perugini \& Bagozzi, 2001). 
The Model of Goal Directed Behavior (MGB) is an extension of the TPB which considers behavioral volitions in the context of purposive behavior, the pursuit of a goal (Perugini \& Bagozzi, 2001). According to Perugini and Conner (Perugini \& Conner, 2000, p. 705), "most behaviors are functional to the achievement of an overarching goal." MGB introduces desire, a construct which "represent[s] the motivational state of mind wherein appraisals and reasons to act are transformed into a motivation to do so" which is similar to Warshaw and Davis's (Warshaw \& Davis, 1985a, 1985b) conceptualization of behavioral goals. These desired end states mediate the effects of attitudes, social norms, and other antecedents to behavioral intentions, thus becoming itself the most proximal determinant of behavioral intention (Perugini \& Bagozzi, 2001; Perugini \& Conner, 2000). Thus the theoretical and practical implications of the distinction between behavioral intention and behavioral goal are evident.

\section{HYPOTHESIS DEVELOPMENT}

An important distinction between behavioral goals and behavioral intention is the assumption of purely volitional behavior, which implies a deliberate intention to behave in a certain way. Goals, unlike intentions, do not assume pure volitional behavior. One may desire to attain the behavioral goal, but impediments may affect whether that behavioral state is achieved (Ajzen, 1991; Venkatesh \& Brown, 2001; Warshaw \& Davis, 1985a). For example, one may have a behavioral goal to adopt a technology (e.g., smart phone). However, high switching costs imposed by a contract impede the actual behavior. Thus, the expected behavior is never realized.

We posit that the time orientation of items used in the measurement of behavioral intention and behavioral goal is key to the distinction between these two constructs. In past IS research, the conceptual boundaries of behavioral intentions measures have been blurred. Some items which claim to measure "long-term" behavioral intention actually may measure behavioral goals. These long-term items cannot measure behavioral intention because pure volitional behavior cannot be assumed for longer durations. Over longer durations, behavior is likely to be influenced by impediments. Therefore, many of these long-term items probably measure behavioral goal rather than behavioral intention. Therefore, we hypothesize that time orientation in questionnaire items related to behavior distinguishes behavioral intentions with a short-term focus and behavioral goals with a long-term focus, and these two constructs are distinct.

Hypothesis: Behavioral Intentions and Behavioral Goals are distinct constructs.

\section{METHOD}

All research methods have strengths and weaknesses (Dennis \& Valacich, 2001). McGrath (1982) proposed that all research methods could be evaluated along three dimensions. The first is generalizability with respect to populations and the second is realism for the participants. And the final dimension is the precision in the control and measurement of variables. It is not only difficult, but impossible, to maximize all three dimensions with any one study (McGrath, 1982). Given that this research is focused on examining measurement items, we have emphasized internal control and precision. This study utilizes a laboratory experiment. Analysis was conducted using structural equation modeling (SEM) with EQS 6.1 software.

\section{Measurement Items}

In order to test the discriminant validity of behavioral intentions and behavioral goals, items were developed to represent three different time orientations for the adoption of a website: 1) website use (no time distinction; e.g., Venkatesh \& Morris, 2000), 2) the behavioral goal of establishing a long-term relationship with a website (e.g., continuance or revisit), and 3) short-term behavioral intention to use the website for an impulse purchase (e.g., impulse purchases - e.g., Koufaris, 2002; Parboteeah, Valacich, \& Wells, 2009). All measures are intended to represent a reflective relationship with the construct of interest (Jarvis, Mackenzie, \& Podsakoff, 2003). These constructs were chosen with the deliberate attempt to keep the context of the constructs constant. All of these constructs are manifest in an eCommerce context with a website. Therefore, the variations of responses from participants can reasonably not be linked to the object of the intention (i.e., website versus some other type of technology), but the time orientation. 


\section{Instrument Development and Pilot Studies}

The development of the psychometric instrument measuring the constructs involved in this study followed the following process: item generation, factor analysis, reliability analysis, and validity analysis. Two separate and independent samples (not included here) were used in this process. An exploratory data analysis was performed on the first sample and the second sample was used to confirm the results of the first (Byrne \& Stewart, 2006). As the first step, a bank of items was generated that could potentially measure the constructs of interest. The first sample of 395 undergraduate students was used for exploratory analysis and a second sample of 275 undergraduate and graduate students was used to confirm the results of the first sample. Results from these samples indicate that the instrument is psychometrically sound. The items that resulted from this development can be found in the Appendix. Further evidence is also provided here.

\section{Variance Manipulations}

Website treatments were created for the purpose of this study. The website represented a fictitious company selling t-shirts - Pac10-tees.com. As this study was used to determine the discriminant validity of constructs related to behavior, treatments were developed that were expected to influence such intentions and goals to provide sufficient variance in these variables. This study employed a 2 (high/low visual appeal) x 2 (high/low website functionality) between-subjects design. Visual appeal was manipulated in the website treatment by having a high/low level of eye-pleasing and professional features. A screen shot of this manipulation is available in Figure 1. Website functionality was manipulated with a 3- to 5-second download delay (present/absent). Manipulation checks of these manipulations supported that participants perceived a significant difference between these conditions.
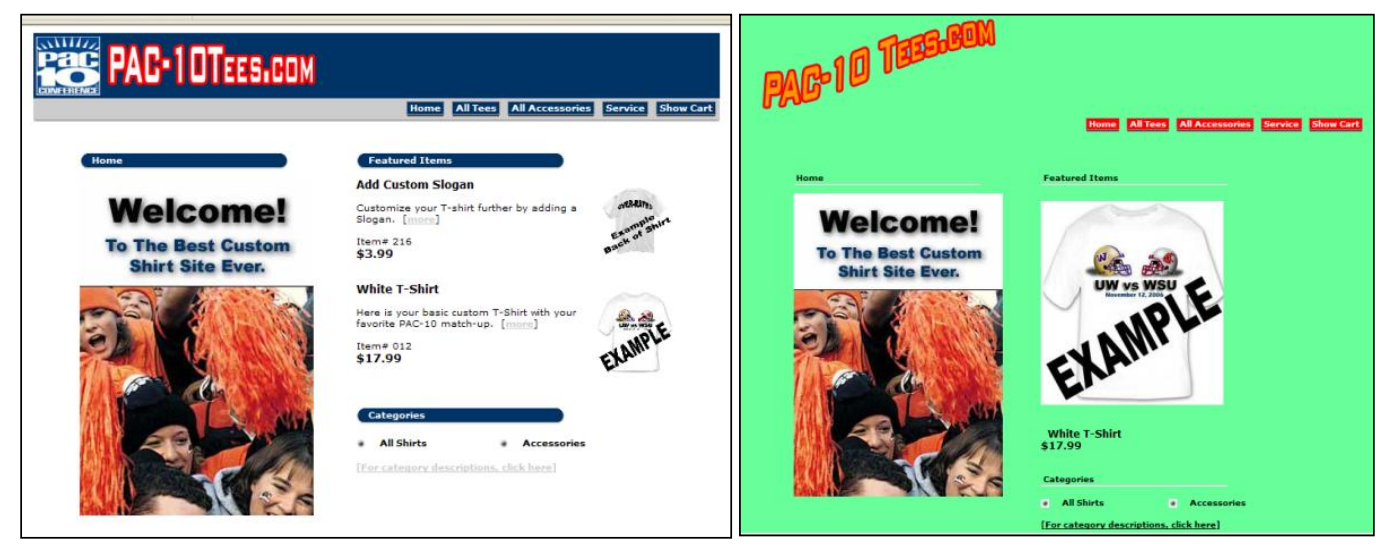

Figure 1: Screen Shots of Web Interfaces

\section{Participants and Task}

The subject pool for this experiment consisted of 458 college undergraduate students from various management information systems courses (upper and lower divisions). The average age of the subjects was 20.54 and there were 302 (62.58\%) men. According to the Pew Internet \& American Life Project (Jones \& Fox, 2005), Internet users are between 18 and 32 years old and this segment of consumers represents one of the largest that actively engages in online shopping. Thus, the students were deemed appropriate for this study. Students received course credit - approximately $1 \%$ of their final grade - for participating in this study.

Subjects were briefed on the procedures of the experiment and participated in an initial survey that gathered basic demographic information. The subjects were then randomly assigned to website treatments. A scenario-based task was used in conjunction with the websites of a fictitious organization. The participants were given a scenario designed not only to expose them to various aspects of the website and increase the realism of the experience, but also to search for and purchase a specific item. After exposure to the treatment, subjects completed a survey instrument. 


\section{Measurement Model}

Table 2 reports an assessment of the measurement model for the three constructs. The reliability analysis for the constructs used the Cronbach alpha and the composite reliability scores calculated from standardized factor loadings (Werts, Linn, \& Joreskog, 1974). Convergent validity was assessed by examining the factor loadings in SEM and the average variance extracted (AVE) of each construct (see Table 3). Discriminant validity was assessed by comparing the AVE of each construct with the squared correlation with other constructs. Convergent validity, discriminant validity, and reliability of the measurement instruments were demonstrated in this sample. Also, the measurement model demonstrated good fit.

Table 2: Summary of Measurement Model Statistics

\begin{tabular}{|c|c|c|c|c|}
\hline Construct & Item & Standard Loadings & Composite Reliabilities & Alpha \\
\hline \multirow{3}{*}{ Short-term Intention } & STI1 & .914 & \multirow{3}{*}{0.955} & \multirow{3}{*}{.954} \\
\hline & STI2 & .958 & & \\
\hline & STI3 & .935 & & \\
\hline \multirow{3}{*}{ Behavioral Goal } & BG1 & .896 & \multirow{3}{*}{0.908} & \multirow{3}{*}{.908} \\
\hline & BG2 & .855 & & \\
\hline & BG3 & .877 & & \\
\hline \multirow{3}{*}{ Intention to Use } & BI1 & .980 & \multirow{3}{*}{0.988} & \multirow{3}{*}{.988} \\
\hline & $\mathrm{BI} 2$ & .989 & & \\
\hline & $\mathrm{BI} 3$ & .978 & & \\
\hline \multicolumn{5}{|l|}{ Fit Statistics } \\
\hline$X^{2} / d f$ & $83.2 / 24$ & SRMR & \multicolumn{2}{|c|}{.024} \\
\hline GFI & .962 & CFI & \multicolumn{2}{|c|}{.990} \\
\hline AGFI & .929 & RMSEA & \multicolumn{2}{|c|}{$.073(.056, .091)$} \\
\hline
\end{tabular}

Notes: The comparative fit index (CFI), the root-mean-square error of approximation (RMSEA), and the standardized root mean square residual (SRMR) are used to evaluate the fit of the measurement and structural models presented in this analysis. The criteria used to evaluate model fit will be that CFI values must be .95 or higher, SRMR values must be .08 or lower, and the RMSEA values must be .08 or lower (Hu \& Bentler, 1999). Composite reliabilities should be above 0.70 (Hair, Anderson, Tatham, \& Black, 1998). Factor loadings showed that the threshold of 0.707 was met for convergent validity (Chin, 1998; Hair et al., 1998; Segars, 1997). Cronbach alpha should be above 0.70 (Nunnally \& Bernstein, 1994).

Table 3: EQS Estimated Squared Correlations and (AVE)*

\begin{tabular}{|l|c|c|c|}
\hline & STI & BG & BI \\
\hline Short-term Intention & $\mathbf{0 . 8 7 6}$ & $\mathbf{0 . 7 6 8}$ & \\
\hline Behavioral Goal & 0.497 & 0.623 & $\mathbf{0 . 9 6 5}$ \\
\hline Intention to Use & 0.530 & & \\
\hline
\end{tabular}

Notes: * AVE figures are shown in bold along the diagonal. Each construct's AVE should be above .50 for convergent validity (Fornell \& Larcker, 1981). Each AVE should be greater than the squared correlations with other constructs for discriminant validity (Anderson \& Gerbing, 1988).

\section{Hypothesis Testing}

Hypothesis testing was conducted using a confirmatory factor analysis (CFA) with covariance-based structural equation modeling to compare the different factor structures. The possible factor structures are 1) that all observed variables measure the same construct (one construct with 9 observed variables), 2) three distinct factors underlie the observed variables, or 3) two factors underlie the observed variables. Therefore, a series of CFAs were conducted for comparison purposes. The interpretation of the results was done by reference to the fit statistics (to determine if the observed data sufficiently supported the theoretical model imposed), $\chi^{2}$ difference tests (appropriate for nested models only), and comparison of the Akaike Information Criterion (AIC) which was developed to compare fit across non-nested models (lower values signify a better fit). See Figures 2 and 3 and Tables 4 through 6 for the results of these CFAs. 


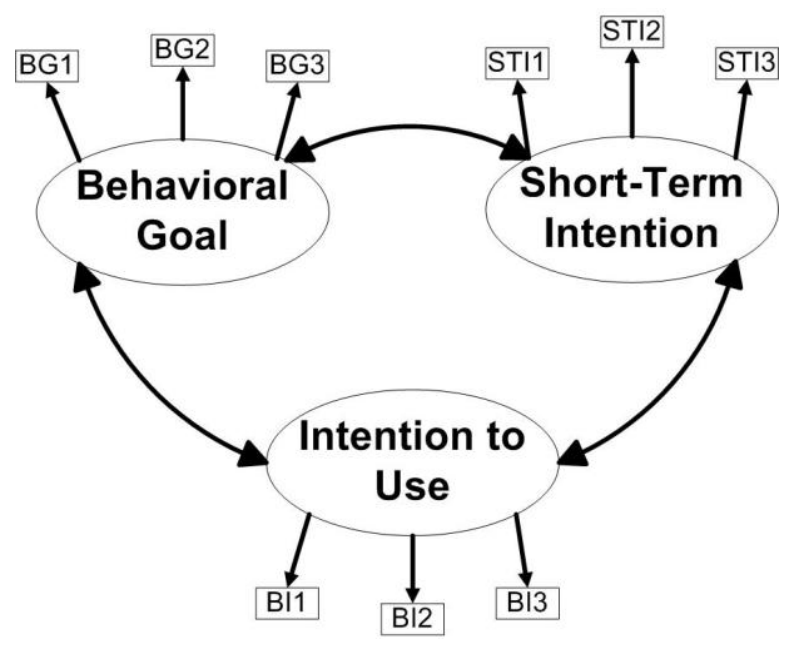

\begin{tabular}{|l|c|c|c|}
\hline \multicolumn{4}{|c|}{ Fit Statistics } \\
\hline $\mathbf{X}^{\mathbf{2}} / \mathbf{d f}$ & $83.2 / 24$ & SRMR & .024 \\
\hline GFI & .962 & CFI & .990 \\
\hline AGFI & .929 & RMSEA & $.073(.056, .091)$ \\
\hline AIC & 35.20046 & & \\
\hline
\end{tabular}

Figure 2: CFA of 3 Factor Structure

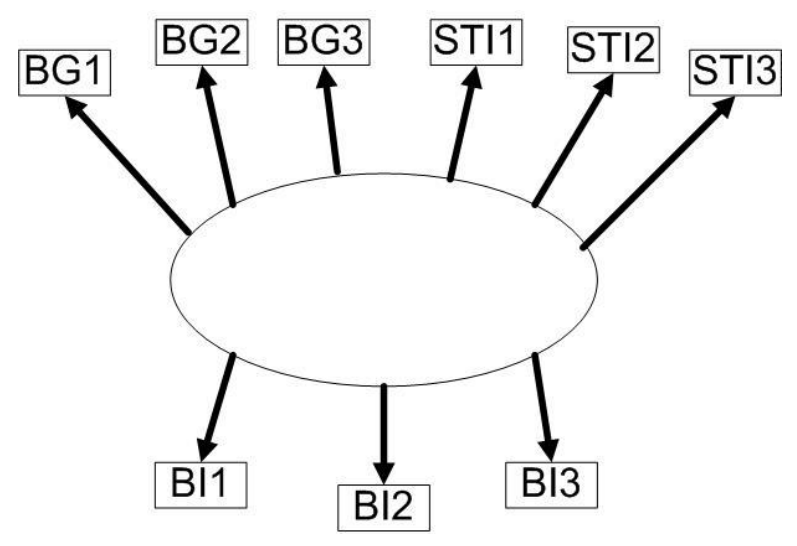

\begin{tabular}{|l|c|c|c|}
\hline \multicolumn{4}{|c|}{ Fit Statistics } \\
\hline $\mathbf{X}^{2} / \mathbf{d f}$ & $1379.308 / 27$ & SRMR & .127 \\
\hline GFI & .587 & CFI & .764 \\
\hline AGFI & .311 & RMSEA & $.331(.316, .346)$ \\
\hline AIC & 1325.30821 & & \\
\hline
\end{tabular}

Figure 3: CFA of Single Factor Structure

By conducting a $\chi^{2}$ difference test of the above nested models, we see that the $\Delta \chi^{2}$ between the nested models is 1296.07 with $\Delta$ df of 3 . This is significant $p>.0001$ (Baker, 2000). We can conclude that these observed variables are most appropriately (according to this sample) modeled with three separate and distinct constructs. This is also supported by the AVE analysis in Table 3. Thus, these results support our hypothesis.

The above figures explicitly test our hypothesis. The following tables summarize the results for 3 additional CFAs which can be used to rule out alternative explanations of the above results by inference and to provide further support for our hypothesis. By examining the possible pairings of the three underlying factors, we can infer that no one construct is driving the poor fit seen in Figure 3. Also, a comparison of the AIC fit statistics shows that these pairings (Tables 4-6) result in poorer fit than the three-factor CFA. 
Table 4: CFA of Single Factor Structure (BI and STI)

\begin{tabular}{|l|c|c|c|}
\hline \multicolumn{3}{|c|}{ Fit Statistics } \\
\hline $\mathbf{X}^{2} / \mathbf{d f}$ & $921.627 / 9$ & SRMR & .146 \\
\hline GFI & .623 & CFI & .792 \\
\hline AGFI & .121 & RMSEA & $.471(.445, .496)$ \\
\hline AIC & 903.62723 & & \\
\hline
\end{tabular}

Table 5: CFA of Single Factor Structure (BI and BG)

\begin{tabular}{|l|c|c|c|}
\hline \multicolumn{3}{|c|}{ Fit Statistics } \\
\hline $\mathbf{X}^{\mathbf{2}} / \mathbf{d f}$ & $417.503 / 9$ & SRMR & .107 \\
\hline GFI & .755 & CFI & .895 \\
\hline AGFI & .428 & RMSEA & $.315(.289, .341)$ \\
\hline AIC & 399.50293 & & \\
\hline
\end{tabular}

Table 6: CFA of Single Factor Structure (BG and STI)

\begin{tabular}{|l|c|c|c|}
\hline \multicolumn{3}{|c|}{ Fit Statistics } \\
\hline $\mathbf{X}^{\mathbf{2}} / \mathbf{d f}$ & $538.947 / 9$ & SRMR & .126 \\
\hline GFI & .693 & CFI & .801 \\
\hline AGFI & .283 & RMSEA & $.359(.333, .384)$ \\
\hline AIC & 520.94749 & & \\
\hline
\end{tabular}

\section{RESULTS}

Results indicate that there is a distinction between behavioral intentions and behavioral goals based on the way items are operationalized. The different time orientation of the items included in this study shows a representation of discriminant factors.

\section{DISCUSSION AND CONCLUSIONS}

The goal of this research was to distinguish between behavioral intentions and behavioral goals. In this article, we provide support for the conceptual difference between behavioral intentions and behavioral goals. Further, the results of this study support the empirical distinction between these two constructs.

The results of this study provide two key insights. As evidenced in the literature review, the intentionbehavior relationship is often taken for granted. Some researchers specify the time orientation when using behavioral intention, but some researchers fail to do so. The results of this study clearly indicate that researchers must be careful in faithfully applying the correct conceptual definition with the appropriate operationalization. In the current study, the distinction between behavioral intentions and behavioral goals was tested and obvious in an eCommerce context, stressing the need for researchers to specify the time orientation of behavioral intention in their studies. In the context of eCommerce, various impediments are existent, such as the availability of alternative products or better deals that might affect the occurrence of the actual behavior. Therefore, we recommend that researchers use caution in operationalizing the time orientation of their items. For example, the use of behavioral intentions should reference relatively short time frames, as opposed to behavioral goals, in the context of eCommerce research unless the researchers are specifically studying continued use, revisit, or customer loyalty.

Our results also have implications for online retailers or e-retailers. At various websites (e.g., Amazon.com), online users have the option of placing items they really want, but cannot purchase at the present time, in a wish list, with the intention of later acquiring the items. Online marketers should offer attractive incentives on these particular items in a timely manner as the longer an item is in the wish list, the lower the probability that the consumer will buy it. Thus, to increase the likelihood that an actual purchase will occur, the marketer should offer attractive incentives that would lead to the consumer buying the product immediately, instead of putting it in a wish list.

As with any study, this study is not without limitations. First, the study involves the use of students as well as scenarios in an experimental setting. This controlled setting limits the generalizability of our findings. Thus, there 
is a need to replicate this study with differing samples in more natural settings to increase the generalizability of the results. In this study, we manipulated two variables; namely, visual appeal and website functionality, to obtain sufficient variance across the variables. However, we did not test the effects these variables had on the dependent variables as this was beyond the scope of the current study. Future research should study the effects of various website factors on these dependent variables.

While the results of our study have important implications, it also points to the need for future research. Future research should examine other types of behavioral intention, not only under the umbrella of TAM, but using other theoretical foundations. For instance, Bhattacherjee (2001b) studied IS continuance intention using the expectation confirmation theory as foundation. Further, as mentioned, the online retail context offers various impediments that can affect the intention-behavior relationship. Thus, future research should study these impediments that lead to changes in intention as well as the enabling factors that will increase the occurrence of the behavior when the antecedent is either behavioral intention or behavioral goal.

\section{AUTHOR INFORMATION}

Damon E. Campbell is an assistant professor of management information systems and Kelley Gene Cook, Sr. Chair of Business Administration at the Else School of Management at Millsaps College. He holds a Ph.D. and MBA from Washington State University. His primary research interests include e-commerce, human computer interaction, and interface design. He has published research in Information Systems Research, Decision Sciences, the Journal of the Association for Information Systems, and AIS Transactions on Human-Computer Interaction, as well as other referred journals and conference proceedings. E-mail: Damon.Campbell@ millsaps.edu (Corresponding author)

D. Veena Parboteeah is an Associate Professor of Information Systems, as well as the MBA coordinator, at Eastern New Mexico University. She received her Ph.D. from Washington State University in 2005. Her research focuses on the design of human-computer interface and the effect of culture on IT adoption. Her research has appeared in journals, such as the Information Systems Research, Journal of the Association for Information Systems, Journal of Organizational and End User Computing, Communications of the ACM, and the Journal of Global Information Technology Management, as well as other journals and conference proceedings. E-mail: Veena.Parboteeah@enmu.edu

\section{REFERENCES}

1. AbdulGader, A. H., \& Kozar, K. A. (1995). The impact of computer alienation on information technology investment decisions: An exploratory cross-national analysis. MIS Quarterly, 19(4), 535-559.

2. Agarwal, R., \& Karahanna, E. (2000). Time flies when you're having fun: Cognitive absorption and beliefs about information technology usage. MIS Quarterly, 24(4), 665-694.

3. Agarwal, R., \& Prasad, J. (1997). The role of innovation characteristics and perceived voluntariness in the acceptance of information technologies. Decision Sciences, 28(3), 557-582.

4. Agarwal, R., \& Prasad, J. (1998). The antecedents and consequents of user perceptions in information technology adoption. Decision Support Systems, 22(1), 15-29.

5. Agarwal, R., \& Prasad, J. (1999). Are individual differences germane to the acceptance of new information technologies? Decision Sciences, 30(2), 361-391.

6. Ajzen, I. (1991). The theory of planned behavior. Organizational Behavior and Human Decision Processes, 50(2), 179-211.

7. Amoako-Gyampah, K., \& Salam, A. F. (2004). An extension of the technology acceptance model in an ERP implementation environment. Information \& Management, 41(6), 731-745.

8. Anderson, J. C., \& Gerbing, D. W. (1988). Structural equation modeling in practice: A review and recommended two-step approach. Psychological Bulletin, 103, 411-423.

9. Bagchi, S., Kanungo, S., \& Dasgupta, S. (2003). Modeling use of enterprise resource planning systems: A path analytic study. European Journal of Information Systems, 12(2), 142-158.

10. Baker, B. (2000). Some useful statistical tables. Retrieved from http://duke.usask.ca/ rbaker/Tables.html, 1. 
11. Bhattacherjee, A. (2001a). An empirical analysis of the antecedents of electronic commerce service continuance. Decision Support Systems, 32(2), 201-214.

12. Bhattacherjee, A. (2001b). Understanding information systems continuance: An expectation-confirmation model. MIS Quarterly, 25(3), 351-370.

13. Bhattacherjee, A., \& Premkumar, G. (2004). Understanding changes in belief and attitude toward information technology usage: A theoretical model and longitudinal test. MIS Quarterly, 28(2), 229-254.

14. Brown, S. A., Massey, A. P., Montoya-Weiss, M. M., \& Burkman, J. R. (2002). Do I really have to? User acceptance of mandated technology. European Journal of Information Systems, 11(4), 283-295.

15. Byrne, B. M., \& Stewart, S. M. (2006). The macs approach to testing for multigroup invariance of a second-order structure: A walk through the process. Structural Equation Modeling, 13, 287-321.

16. Chang, M. K., \& Cheung, W. (2001). Determinants of the intention to use Internet/WWW at work: A confirmatory study. Information \& Management, 39(1), 1-14.

17. Chau, P. Y. K., \& Hu, P. J. (2002a). Examining a model of information technology acceptance by individual professionals: An exploratory study. Journal of Management Information Systems, 18(4), 191229.

18. Chau, P. Y. K., \& Hu, P. J. H. (2001). Information technology acceptance by individual professionals: A model comparison approach. Decision Sciences, 32(4), 699-719.

19. Chau, P. Y. K., \& Hu, P. J. H. (2002b). Investigating healthcare professionals' decisions to accept telemedicine technology: An empirical test of competing theories. Information \& Management, 39(4), $297-$ 311.

20. Chen, L. D., Gillenson, M. L., \& Sherrell, D. L. (2002). Enticing online consumers: An extended technology acceptance perspective. Information \& Management, 39(8), 705-719.

21. Chin, W. W. (1998). The partial least squares approach to structural equation modeling. In G. A. Marcoulides (Ed.), Modern methods for business research (pp. 295-336). Mahwah, NJ: Lawrence Erlbaum Associates.

22. Chin, W. W., Marcolin, B. L., \& Newsted, P. R. (2003). A partial least squares latent variable modeling approach for measuring interaction effects: Results from a Monte Carlo simulation study and an electronicmail emotion/adoption study. Information Systems Research, 14(2), 189-217.

23. Custers, R., \& Aarts, H. (2005). Positive affect as implicit motivator: On the nonconscious operation of behavioral goals. Journal of Personality and Social Psychology, 89(2), 129-142.

24. Davis, F. D., Bagozzi, R. P., \& Warshaw, P. R. (1989). User acceptance of computer technology: A comparison of two theoretical model. Management Science, 35(8), 982-1003.

25. Dennis, A., \& Valacich, J. (2001). Conducting research in information systems. Communications of the Association for Information Systems, 7, 1-40.

26. Dishaw, M. T., \& Strong, D. M. (1999). Extending the technology acceptance model with task-technology fit constructs. Information \& Management, 36(1), 9-21.

27. Fishbein, M., \& Ajzen, I. (1975). Belief, attitude, intention, and behavior: An introduction to theory and research. Reading, MA: Addison-Wesley.

28. Fornell, C., \& Larcker, D. F. (1981). Evaluating structural equation models with unobservable measurement error. Journal of Marketing Research, 18, 39-50.

29. Garrity, E. J., Glassberg, B., Kim, Y. J., Sanders, G. L., \& Shin, S. K. (2005). An experimental investigation of web-based information systems success in the context of electronic commerce. Decision Support Systems, 39(3), 485-503.

30. Gefen, D., Karahanna, E., \& Straub, D. W. (2003). Trust and TAM in online shopping: An integrated model. MIS Quarterly, 27(1), 51-90.

31. Hair, J. F., Jr., Anderson, R. E., Tatham, R. L., \& Black, W. C. (1998). Multivariate data analysis with readings (5th ed.). Englewood Cliffs, NJ: Prentice Hall.

32. Hardgrave, B. C., Davis, F. D., \& Riemenschneider, C. K. (2003). Investigating determinants of software developers' intentions to follow methodologies. Journal of Management Information Systems, 20(1), 123 151.

33. Harrison, D. A., Mykytyn, P. P., \& Riemenschneider, C. K. (1997). Executive decisions about adoption of information technology in small business: Theory and empirical tests. Information Systems Research, 8(2), 171-195. 
34. Hong, W. Y., Thong, J. Y. L., Wong, W. M., \& Tam, K. Y. (2001). Determinants of user acceptance of digital libraries: An empirical examination of individual differences and system characteristics. Journal of Management Information Systems, 18(3), 97-124.

35. Hsu, C. L., \& Lu, H. P. (2004). Why do people play on-line games? An extended TAM with social influences and flow experience. Information \& Management, 41(7), 853-868.

36. Hsu, M. H., \& Chiu, C. M. (2004). Internet self-efficacy and electronic service acceptance. Decision Support Systems, 38(3), 369-381.

37. Hu, L. T., \& Bentler, P. M. (1999). Cutoff criteria for fit indexes in covariance structure analysis: Conventional criteria versus new alternatives. Structural Equation Modeling, 6, 1-55.

38. Hu, P. J., Chau, P. Y. K., Sheng, O. R. L., \& Tam, K. Y. (1999). Examining the technology acceptance model using physician acceptance of telemedicine technology. Journal of Management Information Systems, 16(2), 91-112.

39. Hu, P. J. H., Clark, T. H. K., \& Ma, W. W. (2003). Examining technology acceptance by school teachers: A longitudinal study. Information \& Management, 41(2), 227-241.

40. Jarvis, C. B., Mackenzie, S. B., \& Podsakoff, P. M. (2003). A critical review of construct indicators and measurement model misspecification in marketing and consumer research. Journal of Consumer Research, $30,199-218$.

41. Jones \& Fox. (2005). Pew internet \& american life project. Demographics of Internet Users.

42. Karahanna, E., Straub, D. W., \& Chervany, N. L. (1999). Information technology adoption across time: A cross-sectional comparison of pre-adoption and post-adoption beliefs. MIS Quarterly, 23(2), 183-213.

43. Koufaris, M. (2002). Applying the technology acceptance model and flow theory to online consumer behavior. Information Systems Research, 13(2), 205-223.

44. Lai, V. S., \& Li, H. L. (2005). Technology acceptance model for internet banking: An invariance analysis. Information \& Management, 42(2), 373-386.

45. Loiacono, E. T., Watson, R. T., \& Goodhue, D. L. (2007). WebQual: An instrument for consumer evaluation of web sites. International Journal of Electronic Commerce, 11(3), 51-87.

46. Lou, H., Luo, W., \& Strong, D. (2000). Perceived critical mass effect on groupware acceptance. European Journal of Information Systems, 9(2), 91-103.

47. Lucas, H. C., \& Spitler, V. (2000). Implementation in a world of workstations and networks. Information \& Management, 38(2), 119-128.

48. Mathieson, K. (1991). Predicting user intentions: Comparing the technology acceptance model with the theory of planned behavior. Information Systems Research, 2(3), 173-191.

49. McGrath, J. E. (1982). Dilematics: The study of research choices and dilemmas. In J. E. McGrath (Ed.), Judgment calls in research (pp. 69-80). Beverly Hills: Sage.

50. Moon, J. W., \& Kim, Y. G. (2001). Extending the TAM for a world-wide-web context. Information \& Management, 38(4), 217-230.

51. Nunnally, J. C., \& Bernstein, I. H. (1994). Psychometric theory (3rd ed.). New York: McGraw-Hill, Inc.

52. Ong, C. S., Lai, J. Y., \& Wang, Y. S. (2004). Factors affecting engineers' acceptance of asynchronous elearning systems in high-tech companies. Information \& Management, 41(6), 795-804.

53. Parboteeah, D. V., Valacich, J. S., \& Wells, J. D. (2009). The influence of website characteristics on a consumer's urge to buy impulsively. Information Systems Research, 20(1), 60-78.

54. Peace, A. G., Galletta, D. F., \& Thong, J. Y. L. (2003). Software piracy in the workplace: A model and empirical test. Journal of Management Information Systems, 20(1), 153-177.

55. Pennington, R., Wilcox, H. D., \& Grover, V. (2003). The role of system trust in business-to-consumer transactions. Journal of Management Information Systems, 20(3), 197-226.

56. Perugini, M., \& Bagozzi, R. P. (2001). The role of desires and anticipated emotions in goal-directed behaviours: Broadening and deepening the theory of planned behaviour. British Journal of Social Psychology, 40, 79-98.

57. Perugini, M., \& Conner, M. (2000). Predicting and understanding behavioral volitions: The interplay between goals and behaviors. European Journal of Social Psychology, 30, 705-731.

58. Plouffe, C. R., Hulland, J. S., \& Vandenbosch, M. (2001). Research report: Richness versus parsimony in modeling technology adoption decisions-understanding merchant adoption of a smart card-based payment system. Information Systems Research, 12(2), 208-222. 
59. Riemenschneider, C. K., Harrison, D. A., \& Mykytyn, P. P. (2003). Understanding it adoption decisions in small business: Integrating current theories. Information \& Management, 40(4), 269-285.

60. Saade, R., \& Bahli, B. (2005). The impact of cognitive absorption on perceived usefulness and perceived ease of use in on-line learning: An extension of the technology acceptance model. Information \& Management, 42(2), 317-327.

61. Segars, A. (1997). Assessing the unidimensionality of measurement: A paradigm and illustration within the context of information systems research. Omega, 25(1), 107-121.

62. Taylor, S., \& Todd, P. A. (1995). Understanding information technology usage: A test of competing models. Information Systems Research, 6(2), 144-176.

63. Van der Heijden, H. (2003). Factors influencing the usage of websites: The case of a generic portal in The Netherlands. Information \& Management, 40(6), 541-549.

64. Van der Heijden, H. (2004). User acceptance of hedonic information systems. MIS Quarterly, 28(4), 695704.

65. Van der Heijden, H., Verhagen, T., \& Creemers, M. (2003). Understanding online purchase intentions: Contributions from technology and trust perspectives. European Journal of Information Systems, 12(1), 4148.

66. Venkatesh, V. (2000). Determinants of perceived ease of use: Integrating control, intrinsic motivation, and emotion into the technology acceptance model. Information Systems Research, 11(4), 342-365.

67. Venkatesh, V., \& Brown, S. A. (2001). A longitudinal investigation of personal computers in homes: Adoption determinants and emerging challenges. MIS Quarterly, 25(1), 71-102.

68. Venkatesh, V., \& Davis, F. D. (1996). A model of the antecedents of perceived ease of use: Development and test. Decision Sciences, 27(3), 451-481.

69. Venkatesh, V., \& Davis, F. D. (2000). A theoretical extension of the technology acceptance model: Four longitudinal field studies. Management Science, 46(2), 186-204.

70. Venkatesh, V., \& Morris, M. G. (2000). Why don't men ever stop to ask for directions? Gender, social influence, and their role in technology acceptance and usage behavior. MIS Quarterly, 24(1), 115-139.

71. Venkatesh, V., Morris, M. G., Davis, G. B., \& Davis, F. D. (2003). User acceptance of information technology: Toward a unified view. MIS Quarterly, 27(3), 425-478.

72. Venkatesh, V., Speier, C., \& Morris, M. G. (2002). User acceptance enablers in individual decision making about technology: Toward an integrated model. Decision Sciences, 33(2), 297-316.

73. Vijayasarathy, L. R. (2004). Predicting consumer intentions to use on-line shopping: The case for an augmented technology acceptance model. Information \& Management, 41(6), 747-762.

74. Warshaw, P. R., \& Davis, F. D. (1985a). The accuracy of behavioral intention versus behavioral expectation for predicting behavioral goals. Journal of Psychology, 119(6), 599-602.

75. Warshaw, P. R., \& Davis, F. D. (1985b). Disentangling behavioral intention and behavioral expectation. Journal of Experimental Social Psychology, 21(3), 213-228.

76. Werts, C. E., Linn, R. L., \& Joreskog, K. (1974). Interclass reliability estimates: Testing structural assumptions. Educational and Psychological Measurement, 34, 25-33.

77. Wixom, B. H., \& Todd, P. A. (2005). A theoretical integration of user satisfaction and technology acceptance. Information Systems Research, 16(1), 85-102. 


\section{APPENDIX: SURVEY MEASURMENT SCALES}

\section{Short-Term Intention}

STI1: How likely is it that you would consider using this website for an impulsive, one-time purchase?

STI2: How likely is it that you would use this website for a sporadic, unplanned purchase?

STI3: Even though the occasion may be few and far between, I could see myself using this website for an unexpected purchase.

\section{Intention to Use}

BI1: Suppose you were in the market for one of these products. How likely would you be to purchase though this website?

BI2: $\quad$ Suppose you were in the market for one of these products. How likely would you be to do business with Pac10-tees.com via its website?

BI3: If you were in the market for one of these products, what is the likelihood that you would use this website?

\section{Behavioral Goal}

BG1: I would like to be in a long-term customer relationship with this company.

BG2: Engaging in a long-term relationship with this organization would prove beneficial to me as a consumer.

BG3: Assuming that I was interested in one of their products, I could see myself initiating a long-term relationship with this organization. 
NOTES 